\title{
Lunar new year greetings
}

\author{
Chang-Ju Kim (ib https://orcid.org/0000-0003-4749-5795
}

The new year on the lunar calendar began. The year of 2020, dominated by the damn coronavirus, has passed and the year 2021 has begun with anticipation for vaccines and treatments. Keeping our daily routine from the domination of coronavirus is probably the most important hope of the year.

The first wish of the Korean Society of Exercise Rehabilitation this year is that Journal of Exercise Rebabilitation (JER) will be listed in the SCIE. It has been 3 years passed since JER was enrolled in ESCI, and it is the 4th year. The impact factor of 2020, which was self-examined, is also far exceeding 1.5, so it seems that it is time to be listed as SCIE. The second wish is to invite many speakers to hold an academic conference. I would like to invite many speakers from abroad to host the 2021 academic conference. I want to share not only academic exchanges with them, but also human connection with them at academic conferences.

In addition to these two hopes, I have to talk about the papers submitted to JER. Before submitting a manuscript, reading the "Instruction to authors" of the journal to be submitted and viewing the published manuscript are basic attitude toward writing a manuscript. However, it is also true that there are quite a lot of papers that do not meet the submission rules. In particular, there were many cases of citing numerical references or using "et al." or inappropriate references. All of these mistakes are in the case of submitting an article without reading "Instruction to authors" or a published article at all.

There were quite a lot of papers submitted with insufficient data or with data simply showing the phenomenon. JER wants to go beyond proving the effectiveness of exercise to gain insight into its mechanisms or to identify the underlying mechanism of the disease. Therefore, I expect JER to develop into a platform to share better research results through this process.

In the new year, I hope that everyone who participated in JER publication and submitted papers to JER will be happy. Congratulations on the Lunar New Year and wish you a blessed New Year and all things well.

\section{CONFLICT OF INTEREST}

No potential conflict of interest relevant to this article was reported. 